\title{
Espacios y movilidad de la gente negra en el Pacífico Sur colombiano: ¿hacia la construcción de una "sociedad regional"?
}

Odile Hoffmann

\section{Resumen}

En Colombia, la Constitución de 1991 y la Ley 70 de 1993 reconocen derechos territoriales a las poblaciones negras ribereñas del Pacífico, al atribuirles títulos colectivos sobre territorios ancestralmente ocupados y explotados, previa organización de los campesinos en "Consejos comunitarios" encargados de manejar los territorios en el futuro. El artículo explora las transformaciones que esto implica en la organización regional, basándose en un análisis espacial que recalca tres modelos de estructura socio-espacial. Se puede así combinar tiempos y espacios, y analizar el papel que los distintos actores sociales, económicos y políticos juegan en estas transformaciones.

Palabras claves: territorio, análisis espacial, actores étnicos, comunidades negras, Pacífico, Colombia.

\section{Abstract}

Spaces and mobility of black people in the Colombian South Pacific: toward the built of a "regional society"?

In Colombia, the 1991 Constitution an the Law 70 of 1993 assure territorial rights to the black populations of Pacific coast, attributing them collective titles on the previously occupied and exploited territories and previous organization of peasants under the "Communities Counsels", which are responsible to guide the ethnic 
territory for the future. The article analyze the transformations on the regional organization of this process, based on the spatial analysis that holds three models of social-spatial structure. Therefore, it is possible to combine times and spaces, and analyze the role played by different social, economical and political actors in these transformations.

Keywords: territory, space analysis, ethnic actors, black communities, Pacific coast, Colombia.

\section{Résumé}

Espaces et mobilité des noirs dans le Pacifique sud colombien: vers la construction d'une «société régionale »?

En Colombie, la Constitution de 1991 et la Loi no 70, de 1993, reconnaissent le droit au territoire aux populations noires de la côte du Pacifique par l'attribution de titres collectifs pour des territoires " ancestrales » occupés et exploités, autour l'organisation préalable des paysans dans des "Conseils Communautaires " chargés de diriger ces territoires dans l'avenir. Cet article étudie les transformations que cela implique pour l'organisation régionale, en se fondant sur une analyse de l'espace qui met en relief trois modèles de structures socio-spatiales. On peut ainsi associer les temps et les espaces et analyser le rôle que les différents acteurs sociaux, économiques et politiques jouent dans ces transformations.

Mots-clés: territoire, analyse spatiale, acteurs ethniques, communautés noires, Pacifique côte, Colombie. 
$\mathrm{E}$ n Colombia, los cambios constitucionales y legislativos hacia un reconocimiento del multiculturalismo (1991 y 1993) llevaron a reconocer la existencia de un nuevo actor social, las comunidades negras, y nuevos derechos asociados. Entre ellos, los más significativos en cuanto propiciaron una movilización política extensa, son los derechos territoriales. La Ley 70 de 1993 permite a los campesinos negros organizados en "Consejos Comunitarios" reclamar título colectivo sobre sus "territorios ancestrales", los que vienen ocupando sin título legal, en tierras de la Nación, desde varias generaciones atrás. En su vertiente territorial, la Ley cobija a las poblaciones rurales, ribereñas, del Pacífico: tres características que son restricciones serias ya que cubren una proporción muy reducida de las poblaciones negras en el país. Sólo 13\% de la población negra nacional vive en el Pacífico, y la mitad de ellos residen en las cabeceras, o sea en medio urbano. Conocidas estas limitaciones (y los debates y estudios que merece (cf. Urrea, Ramírez y Viáfara, 2001), queda interesante observar las transformaciones que conocen cerca de un medio millón de personas y sobre todo una región muy extensa, a raíz de una dinámica étnica y territorial nueva a partir de 1991.

Ponemos el espacio al centro del análisis, viendo en éste tanto una construcción social como una dimensión que orienta lo social. Es decir, el espacio es consubstancial a la vida social y política, es producto y productor de sentido social. Los cambios en el espacio geográfico traducen y revelan, mas no corresponden automáticamente a las transformaciones sociales, económicas, culturales o políticas de una región dada. Intervienen múltiples procesos de inercia, de feedback o de autonomización entre los distintos campos de la vida en sociedad, y entre los distintos niveles geográficos -escalas-considerados. La aproximación espacial busca subrayar los procesos de cambio, las rupturas y las continuidades en los dispositivos socio-geográficos. Para esto, a partir de un estudio de caso regional en el litoral pacífico (Tumaco, Nariño), analizamos tres patrones espaciales - "dispositivos socio-espaciales"- que nos 
permiten resaltar los principales motores de los cambios sociales, económicos y políticos.

Aquí un punto de conceptualización se impone. No se trata de describir la evolución de un espacio regional, que iría cambiando con el paso del tiempo. O sea, no suponemos una relación cronológica entre los tres dispositivos socio-espaciales estudiados, menos una evolución lineal en el tiempo de uno a otro. No se trata pues de describir "etapas de desarrollo", en un sentido normalizado, de cuya secuencia hubiéramos sacado tres momentos. Hoy en día los tres dispositivos o modelos coexisten en el Pacífico sur, y veremos como los tres incluyen elementos "tradicionales" y "modernos", es decir, calificados como tales en la etapa actual.

Sin embargo, es imprescindible recordar que un espacio sólo existe en el tiempo, que hereda y forja memoria social, que nunca se puede analizar "independientemente" de su contexto histórico. Algunas configuraciones espaciales tienen antecedentes históricos más lejanos que otras, o van perdiendo fuerza o importancia mientras otra se impone, desde lógicas externas o endógenas, etc. Lejos de ser imágenes "fieles" de la realidad, las configuraciones analizadas aquí son ensamblajes de elementos dinámicos que fijamos por medio del análisis, como "representación" de realidades múltiples de las cuales sólo rescatamos algunas facetas. Representan unas "perspectivas", unas maneras de ver y comprender el mundo, que no excluyen en absoluto otras perspectivas igualmente válidas, pero que remiten cada una a lógicas distintas de organización del espacio y de la sociedad. No habrá pues contradicción en el hecho de que los dos o los tres modelos coexistan en el tiempo, como tampoco se pueden soslayar los procesos de evolución de unas o más características espaciales, debido a procesos mayores que trasforman radicalmente la estructura geográfica de la región (la apertura de una carretera, de un canal, la desaparición de fuentes de empleo, etc.). Los términos de "dispositivos", "configuración", "patrón" o "modelo" pretenden traducir esta complejidad socio-espacio-temporal, sin determinación de una u otra dimensión sobre las demás.

Asumiendo estas limitaciones analíticas, pensamos que la aproximación espacial permite una visión global de los procesos pertinentes localmente. "Global" en cuanto no disocia lo político de lo económico, y estos de lo cultural, etc. Para cada configuración nos obligaremos a cierta disciplina, viendo sistemáticamente los aspectos económicos, territoriales, políticos, y sus relaciones mutuas. Pero "local" en cuanto concierne una extensión espacial 
determinada, y la población que en ella reside: la región sur del Pacífico colombiano.

La Ley 70 de 1993 tiene una doble dimensión, territorial y étnica (Hoffmann, 2001). Territorial en cuanto pretende legitimar derechos agrarios - títulos de propiedad-a sus detentores históricos en una porción precisa del país. Etnica en cuanto subordina estos derechos a la pertenencia de los beneficiarios a las "comunidades negras" entendidas estas como etnia, al lado de los indígenas. En ambas vertientes, las innovaciones legislativas se basaron en el reconocimiento de una "especificidad", agraria y étnica, de los habitantes del Pacífico, es decir en la existencia de una configuración socio-espacial muy peculiar, que se podría calificar como "dispositivo fluvial-ribereño". Veremos cómo, aislada y enfatizada por medio de la reconstrucción conceptual de los legisladores y asesores, esta "especificidad" conforta una imagen "ideal típica" de las comunidades negras rurales en el Pacífico.

El segundo dispositivo analizado aquí -el de la "modernización"-, al contrario, pone el acento en los procesos de indiferenciación y universalidad de las sociedades locales, insertas en procesos globales de escolarización, urbanización y proletarización. A veces se combina con el anterior, a veces le es opuesto, pero los dos siempre se mantienen cercanos y con múltiples nexos -familiares, políticos, económicos.

Finalmente, el tercer dispositivo socio-espacial -el de la “movilización político-étnica”- evidencia la emergencia de configuraciones nuevas, resultados de cruces múltiples entre los anteriores y algunos nuevos, según un proceso de "mestizaje" tal y como lo entiende Gruzinsky (1999): una combinación distinta, nueva, elaborada a partir de elementos tomados de patrones originales diferenciados.

Nuestra argumentación seguirá lógicamente este hilo. ${ }^{1}$ Después de una rápida contextualización geográfica regional, analizaremos los tres dispositivos para responder estas preguntas principales: ¡cómo se trasforman las estructuras espaciales -territorios, redes, lugares nodales?, ¿ cómo intervienen los distintos niveles o escalas, desde lo local hasta lo nacional, en estas transformaciones?, ¿cuáles son los actores que intervienen en estos procesos?, $\mathrm{y}_{\text {¿ }}$ con qué recursos y medios y qué tipo de interacción tienen unos con otros?

"El Pacífico" cubre la franja occidental de Colombia, frente al océano. Admirablemente descritas por West (1957) en los años 1950, las "tierras bajas" del Pacífico son separadas del interior del 
país por la cordillera occidental que funge como un obstáculo a la circulación de hombres y mercancías. Hasta hoy apenas dos vías de comunicación terrestre relacionan el litoral con el mundo andino, al centro y al sur de la región: las carreteras Cali-Buenaventura y Pasto-Tumaco. Fuera de estas, la circulación es fluvial o marítima. Cubiertas de bosques y con una pluviometría que acerca los mayores niveles del mundo (7000 mm anuales en Chocó), estas tierras eran de poblamiento indígena (embera y waunana al norte, awa al sur) hasta la llegada de algunos colonos atraídos por la riqueza aurífera de los ríos (desde el siglo XVI, pero sobre todo en los dos siglos siguientes). Las minas, con su organización social esclavista, sembraron las bases de un nuevo tipo de poblamiento. Después de la emancipación legal de los esclavos (1851) y con la caída de la actividad minera en la zona (fines del siglo XVIII), migraciones importantes de población negra, venida desde el interior del país y los piedemontes mineros, contribuyeron a poblar los ríos, mientras los grupos indígenas se retiraban hacia las cabeceras de los ríos. Así nació una organización social y geográfica original, constituida por pequeños poblados negros distribuidos a lo largo de los ríos, sobre tierras "baldías", al margen de la norma jurídica, y en muchos aspectos de la sociedad nacional.

La zona sur del pacífico siguió estas mismas pautas, pero conoció a fines del siglo XIX y primeras décadas del XX un auge comercial basado en la explotación silvestre del caucho, la tagua y más tarde la madera. Así se instalaron algunos negociantes no negros en el puerto de Tumaco, que se desarrolla desde entonces, con mucha dificultad, hasta volverse una ciudad de 12.000 habitantes en 1951, y 45.000 en 1973.

El análisis concierne a esta región de Tumaco, que corresponde grosso modo al municipio del mismo nombre (120.000 habitantes en 1993, de los cuales la mitad viven en la ciudad misma). Mantiene nexos estrechos con los demás municipios del litoral nariñense, o sea del departamento de Nariño (cuya capital, Pasto, se ubica en la cordillera), y con la ciudad de Cali, metrópoli regional del occidente del país, segunda ciudad del país (2,2 millones de habitantes) y tercera entre las áreas metropolitanas.

\section{El dispositivo fluvial-ribereño: la cuestión del territorio}

Uno de los interrogantes más apremiantes en la actualidad del Pacífico tiene que ver con las aplicaciones y las implicaciones 
de la Ley 70 de 1993 con respecto a la organización territorial. Una primera etapa de la investigación consiste en el análisis de las configuraciones territoriales vigentes antes de la Ley 70. En la zona de estudio, esta fase se llevó a cabo con base en un intenso trabajo de campo en el río Mejicano, en la ensenada de Tumaco (1997-1999). Este río, a unas cuatro horas de Tumaco en canoa, cuenta con cinco veredas principales, de 100 a 600 habitantes, establecidas desde finales del siglo XIX con la instalación de pobladores negros originarios de Barbacoas, ciudad minera vecina ( $\mathrm{Ri}$ vas, 1999).

Las modalidades de manejo y apropiación de los espacios, en este río, muestran algunas características similares a las señaladas para todo el Pacífico en la literatura especializada. Los habitantes explotan los recursos naturales combinando tiempos y espacios: cultivos de vega y de colinos (coco, cacao, arroz), explotación maderera en los interfluvios forestales, pesca en los ríos o en los esteros, cacería, además de una artesanía doméstica (canastas, herramientas). En algunas zonas también perdura una actividad de minería de oro por mazamorreo. Según las temporadas en el año, algunas actividades son más importantes que otras, y no todas son realizadas por todos: hombres y mujeres participan del cultivo, pero la cacería y el trabajo de la madera (y en general todas las actividades realizadas en el bosque) son exclusivamente realizadas por los hombres. Las mujeres se encargan de las labores domésticas. A este sistema polivalente habría que añadir trabajos de extracción silvestre con fines de comercialización, desde por lo menos a fines del siglo XIX. En efecto, los habitantes de los ríos, que son campesinos, pescadores y cazadores, trabajaban también para los negociantes establecidos en la ciudad, para abastecerles en materia prima exportable como la madera fina, el caucho o la tagua (una nuez de palma, también llamada marfil vegetal). Integraban así, al realizar la extracción primaria, las redes internacionales de explotación del medio forestal tropical. Estos negocios se agotaron con la competencia de materias derivadas del petróleo (años 1930-40); sólo sigue la extracción de madera, ya no madera fina cuya exportación fue prohibida en los años 1940, sino de construcción para el mercado nacional (cf. Restrepo y Del Valle, 1996).

La organización social y económica muestra así mismo rasgos compartidos por el conjunto de los pobladores del litoral del Pacífico, debido en gran parte a su historia común de migración y de constitución "reciente" (uno o dos siglos) de los pueblos. Tres aspectos han sido particularmente subrayados en los estudios: en 
el Pacífico las redes de parentesco jugaron un papel preponderante en la construcción de las veredas, y siguen estructurando parte de la vida social local; ${ }^{2}$ el espacio regional se organiza alrededor de la unidad espacial "río" que funge como lugar de reconocimiento social y político, tanto individual como colectivamente (cf. Losonzcy, 1997; Ulrich, 1998); la combinación flexible de actividades económicas supone unas relaciones ambiguas de inserción/dependencia de las producciones campesinas frente a los mercados externos nacionales e internacionales, desde el siglo XIX hasta hoy (por ejemplo con la madera y el coco). Recordemos que se trata de localidades asentadas en terrenos legalmente considerados como "baldíos", es decir que no gozan, en su gran mayoría, de títulos de propiedad. Las normas locales de apropiación son las que rigen el derecho de unos y otros a usar y trabajar las tierras.

A este panorama ya conocido y descrito, la investigación llevada a cabo en Tumaco ha podido aportar precisiones y matices, ya que encontramos fenómenos hasta entonces poco explorados por los estudiosos.

Aun si "el río" aparece como la unidad fundamental de organización y percepción del espacio social, existe una multiplicidad de espacios de referencia a escalas inferiores - la vereda, el estero, el colino -o superiores- la ensenada, la "región" (de Tumaco en este caso), o la gran región del Pacífico. Se evidenciaron distintas modalidades de adscripción y legitimación en un territorio, y su combinación para construir una noción compleja de "pertenencia", que está basada en tres pilares fundamentales: el parentesco, la residencia y el trabajo. Según los contextos locales, será uno u otro registro de legitimación el que será activado, las más de las veces en combinación con los demás. Este sistema polivalente, abierto, integra la flexibilidad de las prácticas migratorias y matrimoniales que amplían singularmente los espacios de convivencia e intercambio (Hoffmann, 1999b).

En el mismo orden de ideas, se nota la flexibilidad de las normas de apropiación y transmisión de las tierras en los ríos (Rivas, 1999): a cada lugar o espacio corresponden ciertas normas locales de apropiación, que pueden variar en el tiempo y en función de los usos y objetivos asociados a los mismos (recolección, cultivos de autoconsumo o de renta, cacería, explotación maderera). ${ }^{3}$ Por un lado se pueden diferenciar reglas de acceso a los "colinos" (parcelas cultivadas por un individuo o una familia) o al "centro" (zona boscosa, de uso colectivo a los habitantes del río) bajo el criterio de la apropiación individual o colectiva. Pero otros matices aparecen, 
cuando por ejemplo se reconoce como legítima la recolección de ciertos productos (silvestres o hasta frutos cultivados como el banano o el coco) en terrenos ajenos, siempre que se trate de recolección para autoconsumo familiar, mientras la misma práctica es socialmente sancionada para otros productos (madera) u otros fines (venta). El criterio de la "subsistencia" se impone al de la apropiación, sin - por lo tanto - acabar en una propiedad común: existen mecanismos locales de regulación y los abusos se ven reprimidos por la comunidad.

Otro de los hallazgos consistió en reconocer una gran variación en las prácticas matrimoniales y familiares de los habitantes rurales. No encontramos un modelo privilegiado de alianza matri-

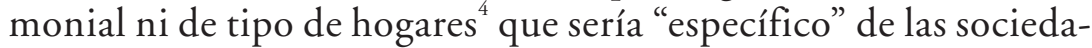
des negras del Pacífico. La matrifocalidad o los hogares extensos no son regla ni siquiera son frecuentes. Encontramos, al contrario, una amplia gama de situaciones (hogares nucleares o compuestos, uniones estables o sucesivas, etc.) que coexisten en una misma vereda, o en el seno de una misma familia, sin que se puedan reconocer regularidades o patrones de comportamiento socialmente valorados. Se resaltan incluso procesos de consolidación y estabilización en las composiciones de los hogares, que se observan sobre todo en las veredas de cierta importancia demográfica ${ }^{5}$ (Hoffmann, 1999b). Esta tendencia se verifica en los hogares afrocolombianos de la capital vallecaucana, Cali (Urrea, 1999), como en los de Tumaco y de los pueblos grandes donde predominan los hogares unifamiliares y nucleares, con promedio de 4 a 5 miembros por hogar y cierta estabilidad de las uniones.

La aproximación multi-escala (la región, el río, la localidad, la familia) pone en evidencia la inserción de los territorios ribereños en espacios regionales de diversa amplitud. Cualquiera que sea la perspectiva adoptada (desde la reproducción económica, las normas de apropiación del espacio, las formas de adscripción territorial, las prácticas matrimoniales o familiares), vemos cómo el universo de los ríos se construye en interacción con otros, a la vez que conserva o adquiere rasgos propios y distintos a los vecinos. $\mathrm{Si}$ bien existen fuerzas que tienden al aislamiento y marginación de los ríos (a nivel económico principalmente), también existen prácticas que apuntan a la comunicación y a veces a la integración regional, por ejemplo mediante las migraciones circulares $y$, de forma mucho más anclada en la cultura del Pacífico, la movilidad de las poblaciones (Vanín 1999). 
La descripción de este dispositivo fluvial-ribereño "tradicional" llevó a cuestionar algunos estereotipos que durante mucho tiempo pesaron sobre los estudios y sobre los mismos habitantes del Pacífico, como son las supuestas especificidades de las poblaciones negras en cuanto a las uniones múltiples, la matrifocalidad, la migración pendular, la propiedad colectiva, etc. ${ }^{6}$ En el Pacífico, las prácticas y las normas de apropiación del espacio, entendidas en su sentido amplio como unas "maneras de estar en el mundo", conforman efectivamente un "sistema" muy distinto al de las poblaciones andinas, por ejemplo. Pero son resultado de construcciones sociales, en tiempos y espacios concretos, y no reflejan una especificidad "cultural" inmutable y perenne.

Este debate sobre la "especificidad cultural" se refleja en las categorías analíticas usadas en las descripciones. Tomaremos el ejemplo del término "campesino", que sigue suscitando polémica entre los estudiosos del tema. Desde hace varios años, Aprile (1992a y 1992b) y Mosquera (2000) ya han descrito el modelo de poblamiento ribereño que asocia el hábitat lineal, a lo largo de los ríos, con un uso y control del espacio rural productivo organizado en "colinos" y "lotes" apropiados individualmente, según una lógica "campesina" de explotación de los recursos naturales. Sin embargo, otros estudiosos refutan esta interpretación, arguyendo de la alta movilidad y precariedad de los asentamientos en el Pacífico, resaltando además el manejo colectivo del espacio (los "centros"). Planteamos que no existen contradicciones entre ambas interpretaciones. Los pobladores negros son campesinos en cuanto tienen una relación privilegiada con el campo, del cual sacan medios de subsistencia y reproducción, y el cual modelan en función de lógicas sociales de negociación y control del espacio, combinando modalidades individuales y colectivas. Es menester aclarar que para nosotros, dado el contexto socio-geográfico del litoral, "ser campesino" supone obviamente combinar las actividades de agricultura con las de pesca, recolección y cacería, así como, cada vez más, el trabajo asalariado permanente o temporal, en los campos o en la ciudad. Se puede explicar la reticencia de ciertos académicos a usar la categoría de "campesinos" por la voluntad de tomar distancia frente a la tradición andina e indígena que tradicionalmente se asocia a esta. Traduce el afán de "particularizar" la situación de los pobladores negros con el fin de contrarrestar la "invisibilidad" de las comunidades negras por parte de los políticos y de las instancias gubernamentales como el INCORA - Instituto Colombiano de Reforma Agraria. Sin embargo, en el plano académico, esta pos- 
tura conlleva el riesgo de "esencializar" una identidad negra "culturalmente distinta", y de soslayar una dimensión socio-económica que los mismos habitantes negros reivindican al nombrarse "campesinos" y/o "agricultores".

Como se puede constatar, esta descripción del dispositivo fluvial-ribereño enfatiza la diversidad y la flexibilidad en las formas de acceso, apropiación y manejo del espacio, así como en las características sociodemográficas de las poblaciones. Estamos frente a lógicas de funcionamiento que no admiten límites fijos ni compartimentos - ni en el espacio ni en la sociedad-, menos aún normas rígidas y fijas en el tiempo. Al contrario, este dispositivo permite la integración y la circulación de hombres y mujeres, así como de ideas y valores, en un espacio globalmente organizado alrededor del río pero no restringido a él. ${ }^{7}$ Podemos reconocer una territorialidad asociada a este modelo, que combina y articula varias escalas (ver figura).

\section{Los referentes espaciales en el sur occidente del Pacífico}

(en las tres situaciones se mantienen lasos con el exterior de la gran región, no representados en los escquemas)

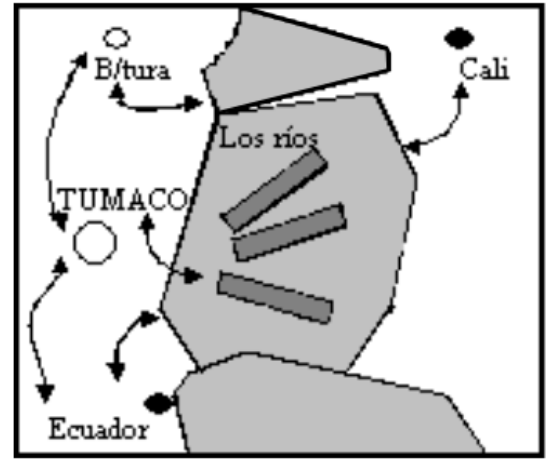

Leyenda: los elementos básicos de la organización espacial

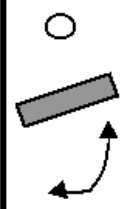

$$
\begin{aligned}
& \text { Puntos }=\text { Ciudades } \\
& \text { (Las capitales en negro) }
\end{aligned}
$$

Extensión $=$ los ríos, los conjuntos de rios

Trazo $=$ redes, comercio, migración

1- El dispositivo fluvial-ribereño

- El río y los ríos vecinos: Movilidad de proximidad

- En articulación con Tumaco ciudad

- Algunos puntos exteriores

- El nivel del río y los ríos vecinos (en el caso del Mejicano, este conjunto lo representa la ensenada de Tumaco) en el que se da la movilidad de proximidad; es el espacio de nupcialidad privilegiado en un primer momento histórico, después de la fundación de las veredas, donde se construyen las primeras redes de parentes- 
co; es también el espacio de relaciones sociales e intercambios diarios (de comida, bienes, servicios, trabajo e informaciones).

- Este ámbito interactúa fuertemente con la ciudad de Tumaco, que se conecta con los ríos al formar parte del espacio de nupcialidad en las generaciones siguientes, pero sobre todo en cuanto lugar de migración, de trabajo, de acceso a servicios públicos (educación y salud) y a veces de doble residencia.

- Más allá de esta bipolaridad (ríos-ciudad), el espacio ribereño siempre mantuvo nexos estrechos con ciertos lugares exteriores a la región inmediata, que fungen como polos de atracción adentro de la gran región del Pacífico (las ciudades de Buenaventura o Cali, o la costa norte de Ecuador). Sea para el comercio o para viajes más duraderos, la movilidad entre estos lugares contribuye a construir y mantener un espacio amplio de referencia, propio de las poblaciones negras, donde se reconocen "en familia".

- Finalmente, no se debe olvidar que los ríos se conectan al ámbito exterior más lejano desde por lo menos el siglo XIX, aunque sea casi siempre en condición subalterna y de discriminación. Este nexo representa el acceso al mercado global y "la modernidad", ambos muchas veces y hasta recientemente en manos de foráneos. Las relaciones entre ambos espacios son esencialmente reguladas por el mercado (negocio de productos de extracción de la selva como la tagua, el caucho, la madera).

Este dispositivo espacial escalonado, desde lo micro local hacia lo regional, se asocia a un dispositivo de control político marcado por la fragmentación entre múltiples jefes políticos locales, cada uno manejando los espacios locales de los ríos, integrados a redes laxas del partido liberal (por razones históricas, el partido conservador nunca alcanzó grandes fuerzas en el Pacífico sur, cf. Agudelo, 1999). En el plano económico, traduce la yuxtaposición, y en ocasiones la combinación, entre distintas lógicas de producción y acumulación, de autoconsumo y sobrevivencia asociadas a actividades de extracción y monetarización, estando las primeras en posición de subordinación sistemática frente a las segundas. El sistema regional de poder político conforta esta marginación de "los ríos" que se sobrepone a la diferenciación socio-étnica: las poblaciones negras están asociadas al espacio local rural; los blancos urbanos, deciden y se encargan de las relaciones con la esfera global. Es de notar que esta configuración traduce un sistema de dominación pero no corresponde a realidades de segregación espacial desde hace por lo menos medio siglo: hoy la ciudad de Tumaco es predominantemente habitada por moradores negros (hasta un 
90\% según informes municipales de 1998). Hasta los años 1990, se puede decir que nadie del exterior se interesa por el Pacífico rural, ni el Estado y sus instancias de gobierno, ni el sector político nacional que lo deja todo en manos de algunos poderes locales, ni siquiera la Iglesia que empieza a movilizarse a fines de los años 1980.

Este "modelo" socio-espacial, con todas las riquezas socioculturales que significa para las veredas negras, por un lado, y todas las frustraciones que implica para sus poblaciones rurales marginadas, por otro, era generalizado en el litoral pacífico hasta los años 1950. Sigue vigente y dominante en la mayor parte de la región hasta hoy. Retomando aspectos parciales del mismo, e interpretándolos bajo la luz de las "especificidades culturales" de las poblaciones negras, varios académicos y militantes lucharon por el reconocimiento de derechos territoriales en el Pacífico, dando paso a la formulación de la vertiente territorial de la Ley 70 (Arocha, 1999; Wade, 1994; Hoffmann, 1998; Agudelo, 1999). Querían así prevenir un acaparamiento de tierras y un despojo de territorio que se venían dando en algunas partes con gran celeridad, como lo vemos en el segundo modelo propuesto.

\section{La modernización en el Pacífico Sur (años 1950-70)}

A partir de los años 1940-60, la llegada de capital agroindustrial foráneo a la región del litoral, sea bogotano, valluno o de los Llanos (además de algunos extranjeros que históricamente siempre han estado ahí), conlleva nuevas formas de explotación de los recursos locales y del trabajo: intensificación del asalariado, proletarización del o la trabajador(a) y su familia. Explotación masiva de la madera en terrenos "baldíos" dados en concesión a grandes empresas, haciendas ganaderas, plantaciones de palma africana y piscinas de camaronicultura, contribuyen a trastornar el paisaje del litoral, sobre todo en los alrededores de la ciudad de Tumaco.

Esta dinámica está apoyada por el Estado en dos vertientes principales: la asistencia técnica y la regularización en la tenencia de la tierra. La primera se traduce por la implantación de una estación agronómica en Tumaco, destinada a difundir las tecnologías apropiadas a los sistemas "modernos" de producción (semilla mejorada, pesticidas y fertilizantes), sobre todo para el arroz por el lado campesino, la palma africana por el empresarial. La "regularización” de la propiedad está a cargo del INCORA. Esta institución 
procede a entregar títulos individuales de propiedad sobre algunos predios campesinos, muchas veces asociando la entrega del título al otorgamiento de créditos agrícolas por la Caja Agraria para "cultivos tecnificados" (arroz principalmente). Los fracasos técnicos llevan en numerosos casos al no reembolso de créditos, seguido de embargos por parte de la Caja Agraria que vende los predios a los grandes empresarios ganaderos y/o agrícolas. Así, la "modernización agrícola" en esta zona se traduce en pérdida de tierras y de recursos para los campesinos (Agier, 1999a), y en el desarrollo espectacular de haciendas ganaderas y de palma africana alrededor de la carretera Pasto-Tumaco (años cincuenta y sesenta).

En otras partes del litoral nariñense intervinieron también razones "naturales" para socavar la viabilidad del sistema anteriormente descrito: una plaga afectó los cultivos de coco desde Timbiquí hasta la frontera, en 1972-74, y, sobre todo, el maremoto de 1979 dejó muertos y tierras cubiertas de aguasal, inservibles por muchos años, provocando salidas y migraciones hacia las cabeceras municipales, y a veces hacia el exterior (Tumaco y Cali).

Mención especial se debe a un fenómeno "socio-natural": la apertura del "canal Naranjo", en 1979, en la parte central-norte del litoral nariñense. Ese año, un negociante decidió abrir un canal pequeño entre los ríos Sanquianga y Patía, para facilitar el transporte de sus trozos de madera hacia el norte, sin contar con un desnivel de varios metros entre las dos extremidades del canal, y con la fuerza de las aguas que modificaron drásticamente sus cursos. El río Patía, el más importante de la zona, cambió de rumbo, reorientando de esta manera los flujos de mercancía, actividad y dinero hacia el norte. Los pueblos instalados sobre el viejo río perdieron su medio de comunicación y sus recursos haliéuticos, mientras las pequeñas localidades del norte se convirtieron brutalmente en pueblos nodales para la actividad económica (extracción forestal). Los compradores de madera llegaron, con su cortejo de trabajadores, comerciantes, prostitutas, aventureros y otros menos bienvenidos (narcotraficantes, paramilitares). Estos cambios en la configuración espacial y socioeconómica regional provocaron la ruptura de los lazos de la zona norte Nariño con el puerto de Tumaco, y su acercamiento al de Buenaventura. ${ }^{8}$ También significaron trastornos ecológicos (agotamiento de recursos marinos) y físicos (en las intensidades y direcciones de las corrientes fluviales y marítimas) que amenazan a pueblos enteros.

Estas décadas representan entonces, en tiempos y por factores variados según los lugares, años de transformación drástica 
para los campos del pacífico sur. El modelo de campesinado móvil y múltiples recursos (caza, pesca, madera) se vuelve insostenible y este se inserta cada vez más, en condición de dependencia aguda ya que no dispone de capital ni asistencia técnica, en las nuevas estructuras de producción, trabajo y comercialización impulsadas por el capital agroindustrial y maderero.'

Los patrones de territorialidad evolucionan también bajo el impulso de otras dimensiones de la modernización: la generalización de la escolaridad, la difusión de medios masivos de comunicación, y la aceleración de la emigración que llega a superar, en intensidad, a la tradicional movilidad y circulación de proximidad. El tríptico identificado anteriormente como fundamento de la pertenencia territorial -residencialparentescoltrabajo- se desbarata ya sea brusca o paulatinamente, según los casos.

Los sistemas de residencia incluyen ahora nuevas modalidades, como la doble residencia (río-Tumaco) y la emigración de hombres y sobre todo mujeres jóvenes a Tumaco y Cali mientras se debilitan los lazos inter-ríos. Paralelamente las redes de nupcialidad se distienden y abarcan nuevos espacios o puntos (los de emigración), modificando profundamente las relaciones de parentesco que solían estructurar los espacios rurales. Tercer pilar del modelo anterior, el trabajo mismo ya no es suficiente para asegurar la reproducción social, ni siquiera familiar, en el río (agotamiento de las buenas tierras y problemas de producción ya evocados).

Producto de estas dinámicas, la ciudad de Tumaco conoce un crecimiento demográfico sin precedente (dobla su población entre 1960 y 1973). Familias enteras, o mujeres con sus hijos van a la ciudad en busca de mejores opciones para la escolaridad y la salud. Los jóvenes encuentran trabajo en los aserraderos que por estos años (1960-70) se multiplican (cf. Restrepo, 1997) o en las plantaciones de palma africana recién instaladas. Las jóvenes salen del campo, preferencialmente para Cali o las grandes ciudades del país, muchas veces para emplearse en el servicio doméstico. La población de la ciudad de Tumaco cambia con estas olas de migración -algunos hablan de la "recolonización negra" de la ciudad, anteriormente dominada por las élites blancas -, pero las infraestructuras (agua, luz, viviendas) no siguen el ritmo, desembocando en una fisonomía urbana fragmentada y altamente marginada (Restrepo, 1999).

Este franco abandono de la región sureña se debe entender también a la luz del sistema político regional que impera en estos años, a saber un gamonalismo exacerbado (cf. Helfrich, 1998) li- 
derado por Alberto Escrucería -conocido como Beto. Este jefe político liberal logra tener un casi monopolio político en esta región durante 30 años (1950-80), con base en un clientelismo muy personalizado por un lado, y el apoyo pasivo de los grupos liberales a escala nacional por otro. La "edad de oro" del "betismo" aprovecha la modernización y el crecimiento de Tumaco para consolidar su feudo, logrando adhesión popular al enaltecer la "identidad tumaqueña", explotando de esta manera los viejos antagonismos geopolíticos entre el litoral -población negra, liberales- y la sierra vecina-población andina, conservadores (Hoffmann 1999a).

Frente a las innovaciones económicas y territoriales arriba mencionadas, muchos nativos rurales mencionan los procesos de ruptura que vivieron, frente a la pérdida de sus tierras o de su autonomía. Pero no existen, en aquella época, formas de expresión colectiva que traduzcan este malestar. El dispositivo político está bloqueado por el "betismo", y las movilizaciones populares todavía no se desarrollan. Sin embargo, empiezan a elaborarse estrategias de adecuación a las nuevas lógicas. Al principio son individuales, pero anuncian cambios culturales y sociales que tienen implicaciones sobre la configuración regional. Así por ejemplo, se notan nuevas solidaridades entre el campo y la ciudad, en las que las redes de parientes juegan un rol decisivo. Son ellas las que, en un primer momento, permiten la instalación de los nativos de los ríos en la ciudad -migración- o más puntualmente les abre los espacios urbanos que necesitan (salud, escuela, diligencias administrativas). Los campesinos se van apropiando de la ciudad y empiezan a dejar su huella en la fisionomía urbana, en las viviendas por ejemplo (cf. Alvarez, 1998). Se construye así una nueva identidad tumaqueña que incluye a los migrantes de origen rural. La "especificidad" rural se desvanece; los habitantes de los ríos experimentan una diversificación de sus modelos de territorialidad y se acentúa cada vez más la combinación de actividades rurales y urbanas. En esta dinámica el polo urbano de Tumaco funge como el referente principal de los habitantes de la región, tanto rurales como urbanos. Se vuelve "ciudad" verdadera hacia la década del noventa, aunque todavía no logra consolidarse como modelo urbano complejo y acabado (cf. Agier, 1999b).

La configuración espacial que resulta de estos procesos políticos, económicos y territoriales se distingue de la anterior por sus tendencias a la fragmentación y dislocación espacial, a la vez reflejo y factor de dispersión de los actores locales. Los "territorios" lo- 
Los referentes espaciales en el suroccidente del Pacífico

(En las tres situaciones se mantienen lazos con el exterior de la gran región, no representados en los esquemas)
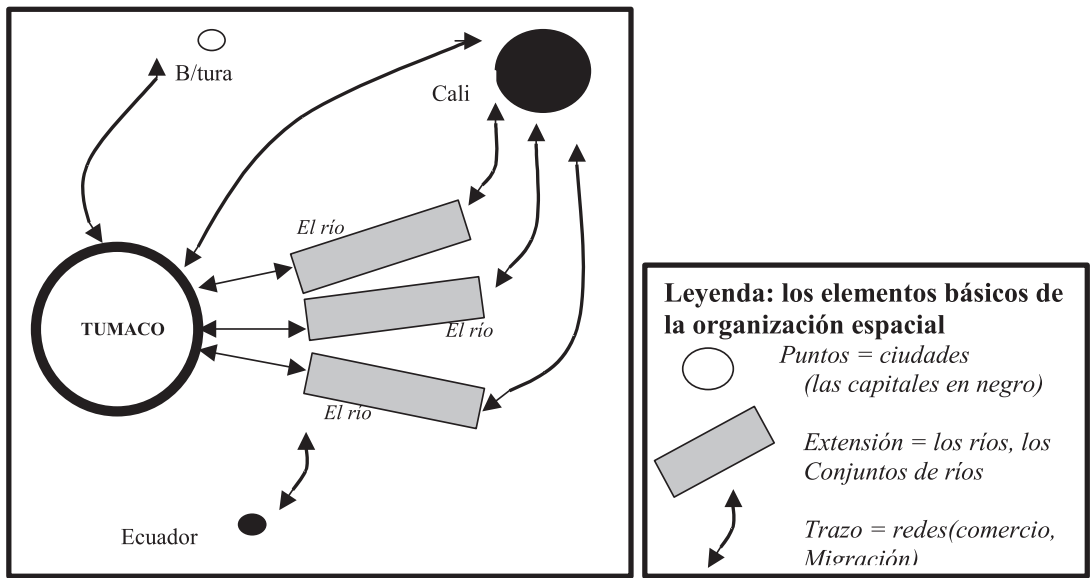

2- El efecto de la modernización

- Se encogen los espacios locales

-irrupción de agentes externos potentes

-sube en importancia Tumaco, y sobre todo Cali

-Se multiplican redes de migrantes

cales, rurales, cambian de morfología, a la vez que las redes se reorientan en el espacio geográfico y social. Veamos.

- Se encoge el espacio local ribereño. Las relaciones entre ríos se debilitan, y las territorialidades tradicionales pierden piso a medida que se afianzan relaciones diádicas entre cada río y la ciudad. Este fenómeno es claramente perceptible al analizar los espacios de nupcialidad que cada vez más se estructuran alrededor de la ciudad de Tumaco (la mayoría de los cónyuges de los nativos de los ríos son originarios de la ciudad). Pero igualmente se constata, en una menor frecuencia, de intercambios económicos y políticos entre ríos, a favor de relaciones de cada uno con la ciudad.

- Correlativamente se imponen los polos urbanos como parte íntegra de los espacios ribereños: Tumaco, como ya hemos notado, pero también Cali, destino de emigración temporal y muchas veces definitiva, todavía más para las mujeres que para los hombres. Se consolidan las redes de migración, en las que las relaciones de parentesco y de paisanaje juegan un papel fundamental (Arboleda, 2001; Urrea y Murillo, 1999). No hay pues disociación entre territorio rural y redes de migración hacia las ciudades, unos y otras se confortan mutuamente. 
- La principal innovación reside en el lugar cada día más imponente que ocupan agentes económicos externos muy potentes, como son el capital agroindustrial (palma africana) y maderero; en algunas zonas de la región, las mejor ubicadas y de mejor calidad agronómica, llegan a controlar tanto el acceso a las tierras como las fuentes de empleo, lo que hace de ellos los principales actores del dispositivo socio-espacial.

- En este contexto geo-económico, se afianza el control político de la región desde el clientelismo "betista", asociado a la poca presencia del Estado central. Es más, como se puede ver en la actualidad, se establecen alianzas políticas entre los gobiernos municipales y el sector agroindustrial, llegando así a un control multidimensional de la región.

Es difícil, en esta configuración, reconocer un "espacio regional" coherente. Se trata más bien de un conjunto de redes yuxtapuestas que activan la migración (y son activadas por ella), en articulación con territorios que, si bien se mantienen como espacio de reconocimiento cultural y social para sus miembros, no cumplen la función de reproducción que les correspondían anteriormente.

\section{Tiempos de movilización étnica: vuelve el territorio}

En Colombia el contexto nacional de los años 1980 está marcado por las medidas de apertura económica, descentralización y democratización, ${ }^{10}$ y por las dinámicas políticas que desembocan en la Constituyente y la Constitución de 1991 y posteriormente en la Ley 70 de 1993. Esta oleada de reformas fue precedida por fuertes movilizaciones políticas en todo el país (numerosos paros cívicos y protestas), expresiones de la crisis del modelo clientelista redistribuidor. Este conjunto heterogéneo de reformas, rupturas y participación popular también se dio en el Pacífico sur, asociado a procesos regionales de transformación económica, política y de reivindicación identitaria.

A nivel económico, se acentúa el afianzamiento del capital agroindustrial alrededor de Tumaco (cf. Escobar, 1996) con una presión creciente sobre los recursos en tierras y trabajo en la zona de la carretera, para ampliar las áreas de palmicultura que hoy sobrepasan los 20.000 hectáreas (CEGA, 1999). El fracaso del intento de industrialización maderero en los años 1970, aliado a la precarización de la agricultura campesina y de la pesca artesanal frente 
a los industriales, provoca un desempleo muy alto y un descontento generalizado que encuentra expresiones variadas.

La movilización popular suscita, a la vez que se fortalece con ella, la emergencia de actores locales apoyados por las ONGs (Plan Padrino), los programas de desarrollo que por estos años se implementan en el Pacífico -en Tumaco es sobre todo la $\mathrm{CVC}^{11}-$ y la Iglesia católica que inicia una línea de Pastoral negra en los años 1980. Sean masivas o puntuales, a veces violentas, ${ }^{12}$ estas expresiones populares (cf. Pardo, 1997) participan de una misma reivindicación de protagonismo frente a un Estado ausente y un capital cuyas lógicas y exigencias invaden todas las esferas de la vida regional. Las vías tradicionales de negociación clientelista se agotan y el "betismo" se debilita -y con él algunas redes regionales del litoral nariñense ligadas al caudillo-, mientras se estructura una competencia político-electoral alrededor de fracciones locales del liberalismo (cf. Helfrich, 1998; y también Hoffmann, 1999a).

Nacida de la misma demanda por más participación, en el contexto de la Constituyente, otra vertiente de la movilización se organiza en torno a la reivindicación étnica negra (Agudelo, 1999a). La coordinación regional del Proceso de Comunidades Negras -Palenque (en un principio unificada y hoy bastante fragmentada y debilitada) - acompaña las organizaciones de base para constituir consejos comunitarios y promover la titulación de territorios colectivos, en el marco de la Ley 70. En este proceso, campesinos, líderes y asesores externos combinan esfuerzos, y a veces se enfrentan entre sí, para elaborar los expedientes necesarios a la titulación colectiva de las tierras de las comunidades negras (cf. Villa, 1998). Esto implica seguir las pautas marcadas por la Ley, entre las cuales está la necesidad de reconstruir la memoria social y geográfica de la comunidad (historia de la fundación y genealogías). Esto significa llevar una reflexión colectiva acerca del territorio, de la identidad, y de la relación entre ambos. Se trata pues de construir consensos -o de lograr imposiciones- en torno a nuevos conceptos que van asociados a la figura de "territorio colectivo de comunidades negras": la identidad étnica, la gestión colectiva, pero también el significado y el papel de nuevas instituciones locales como el Consejo Comunitario, la Asamblea de Pobladores o la Junta de Gobierno, entre otras.

La titulación de territorios colectivos, lejos de reducirse al simple reconocimiento de derechos territoriales anteriormente adquiridos, determina nuevas formas de manejar y dividir el espacio y nuevas relaciones entre los actores interesados. En este largo 
caminar, los campesinos a veces se apropian de nuevas técnicas y modos de pensar su espacio, por ejemplo mediante la elaboración de mapas y la reconstrucción histórica de sus territorios. Por su lado, los asesores y militantes, urbanos en su mayoría, aprenden o reaprenden valores "rurales" y pueden llegar a modificar algunos de sus planteamientos teórico-políticos para tomar en cuenta ciertas prácticas locales que habían soslayado (Hoffmann, 2000a). Se da así, alrededor del espacio local y de su control, una interacción entre ámbitos sociales distintos pero reunidos en esta ocasión — la solicitud de titulación.

A la fecha (octubre 2001) se realizaron once titulaciones de territorios colectivos de comunidades negras en Nariño (concernientes a 155 localidades y 360000 hectáreas), mientras otras tantas están en trámites ( 21 solicitudes, para 270 localidades y 430 000 hectáreas, cf. INCORA, 2001). La titulación de los territorios colectivos de la Ley 70 conoce una aplicación diferencial en función de los actores presentes. En Chocó donde se planean macroproyectos y donde se enfrentan guerrillas, paramilitares y narcotraficantes, los beneficiarios campesinos de los territorios recién titulados son masivamente desplazados por las violencias. En $\mathrm{Na}$ riño los territorios eran hasta hace poco tiempo relativamente poco codiciados por estos actores, lo que permitió una movilización campesina y un proceso de titulación conforme a la Ley (con todos los matices amparados por las ambigüedades de la misma, cf. Agier y Hoffmann, 1999). Pero, como lo veremos más adelante, los recursos económicos y geoestratégicos de la región sur también despertaron el interés de muchos actores legales e ilegales, armados o no, cuyo "encuentro" y confrontación llevan, hoy, al aumento espectacular de la conflictividad regional (Sánchez, 2001; Hoffmann, 2001).

La interacción entre los niveles nacionales, regionales y locales, por una parte, la retroalimentación entre procesos políticos, económicos y culturales, por otra parte, desembocan en la última década en profundas transformaciones en las lógicas del "funcionamiento" regional. Entre otras, la dimensión migratoria adquiere otro matiz, con impactos evidentes en las estructuras demográficas de los lugares de expulsión y de llegada. Las tendencias demográficas en el Pacífico se acercan a los perfiles generalizados en el país, marcados entre otras características por unas tasas de masculinidad altas en el campo y una feminización de las ciudades. No salen los más jóvenes, ni los más pobres, sino que se nota un aumento de migración de sectores con mayor capital escolar. Los destinos mis- 
Los referentes espaciales en el suroccidente del Pacífico

(en las tres sinuaciones se mantienén lazos con el exterior de la gran región, no represemados en las esquémas.

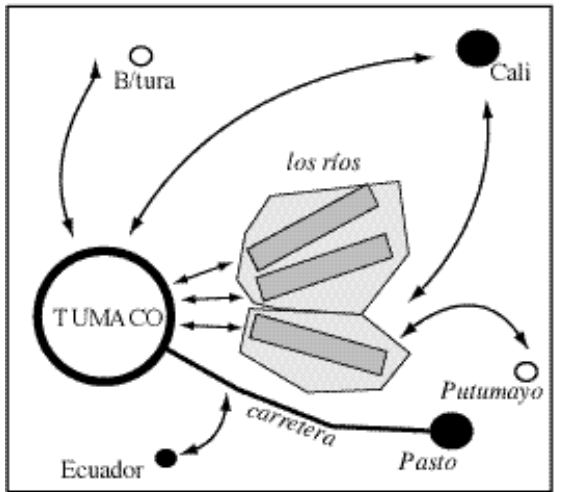

Leyenda : los elementos básicos de la organización espacial

Puntos $\mathrm{z}$ ciudades

(las capirales én negro)

extensión $=$ los rios, los conjuntos de rios

trazo $=$ rédes (comercio, migración)

3 - ¿hacia la integración?"

-revalorización de los rios en cuanto territorios (Consejos comuniarios)

-sigue el polo de Tumaco

- mayor integración con Pasto

-disminuye la imp. de Cali y aparecen otras redes (Putumayo)

mos de migración se diversifican. Al lado de Cali y Ecuador aparecen Nariño-interior, Putumayo, Venezuela (encuesta en el río Mejicano 1998; y Vanín, 1999). Sin embargo, es notorio que algunas de estas redes se consolidan, especialmente las que unen la región de Tumaco con Cali.

Se pueden hacer varias lecturas políticas de esta nueva configuración socio-espacial, entre ellas dos principales: una que apunta hacia la construcción de una sociedad regional, otra que enfatiza las fuerzas de fragmentación del espacio social y político. Serían como dos posibles escenarios futuros, que presentamos antes de describir, en conclusión, una situación presente más bien aterradora.

- hacia la construcción de una sociedad regional - Los últimos años propiciaron la emergencia de actores locales más potentes, diversos y numerosos. Hoy los líderes de las organizaciones étnico-territoriales, pero también los políticos, las ONGs o los gremios pueden acogerse a instrumentos de legitimación nuevos y reconocidos como son la Ley 70, las medidas de descentralización o el interés renovado del gobierno central para la zona, por razones político-estratégicas. Para los pobladores negros, y aunque sea de manera dispersa y fragmentada, se elaboran nuevos espacios de au- 
tonomía alrededor de los territorios colectivos titulados y de un vasto "territorio-región" de las comunidades negras en el Pacífico. Esto les permite asegurar el control de las tierras a la vez que les abre nuevas vías de inserción en los programas, gubernamentales o no, que se encargan de financiar proyectos alternativos de desarrollo en el Pacífico. El territorio se vuelve recurso en sí, sobre todo en el marco de proyectos de "desarrollo sostenible" que pretenden privilegiar las comunidades campesinas y étnicas por su papel en la conservación de los recursos naturales. Como se analizó con detalle en un consejo comunitario (ACAPA, municipio de Pizarro), la titulación colectiva puede dar paso a un empoderamiento por parte de las comunidades o de algunos de sus líderes - con sus evidentes limitaciones-, llegando incluso a fomentar una nueva institucionalidad local basada en la defensa de la biodiversidad (Rivas, 2000). Por otro lado, cierto desarrollo económico se da alrededor de las actividades agro-industriales y del desarrollo urbano, con pasos hacia la integración con la sierra vecina y el interior del país (Pasto). La marginación geográfica de la región frente al país, eterna fuente de queja por parte de los tumaqueños, tendría a disminuir. Estos dos "pilares" de la dinámica regional -los territorios negros y el sector agroindustrial-se apoyan en recursos y discursos legitimados de afuera pero reapropiados y movilizados por actores locales (discurso étnico y biodiversidad por un lado, progreso económico e integración macroregional por otro).

La sociedad regional se podría desarrollar con base en la complementariedad entre estos dos proyectos, siempre y cuando existan canales de discusión y negociación entre ambos. En el contexto del Pacífico el término "sociedad regional" no es neutro ni retórico. En efecto el vocablo "sociedad" casi no se oye cuando se habla del Pacífico, que todavía se percibe como un espacio donde viven "grupos", "poblaciones", "comunidades", "veredas", "gente", palabras seguidas inmediatamente del adjetivo "negro" o "negra". La concepción mayoritaria sigue viendo en el Pacífico colombiano un conjunto de entidades sociales elementales y separadas, significantes sobre todo por su pertenencia étnico-racial. De alguna forma, se opone, tal y como lo hacía Tönnies (1922) en su teoría clásica, la "sociedad" (gesellschaft), noble en su modernidad, a la "comunidad" (gemeinschaft) reducida a ciertos territorios y ciertos registros de legitimación. ${ }^{13}$ La noción de "comunidades negras" elaborada desde la Constitución por intelectuales y militantes étnicos, reviste ciertamente otro significado, que entre otras cosas rebasa fronteras geográficas para proponer un sentido "ciudadano" 
de la identidad étnica. Las "comunidades negras" de hoy se reivindican como parte activa de la Nación y de la modernidad. Sin embargo, esta innovación conceptual y política no puede borrar siglos de estigmatización y de reducción de toda una población organizada a su sola característica "cultural" o "racial". Proponer acuñar el término de "sociedad regional" traduce la voluntad de desparticularizar el Pacífico, reconociéndole unas dinámicas sociales, económicas y políticas que se entienden por el contexto actual y sus antecedentes históricos, más que por una supuesta "especificidad cultural" negra. En cuanto miembros de una "sociedad regional" como existen otras en el país (la región paisa, la región costera, etc.), los habitantes se entienden como ciudadanos, a la vez que como "comunidades negras".

De la misma manera, el término región (más común es cierto) representa todavía un reto para los habitantes, las organizaciones y los políticos para concebir acciones que derivan en una verdadera construcción regional. No es casualidad que la Agenda XXI para el Pacífico (2000) haya adoptado como lema "Hacer región", en aras de juntar iniciativas y propuestas de desarrollo para los próximos 25 años.

- La segunda interpretación resalta los factores de posible fragmentación social, política y territorial. Las dinámicas actuales consolidan lógicas político-territoriales por parte de grupos que se legitiman en registros distintos, llegando en concreto a una yuxtaposición de espacios de estatutos diversos: territorios colectivos de comunidades negras, resguardos indígenas, grandes plantaciones privadas, concesiones madereras, reservas naturales, etc. Pero el espacio no es extensible, y empiezan a darse situaciones de competencia territorial que adquieren matices étnicos, socioeconómicos o políticos según los casos. Cada "grupo" lucha por obtener recursos propios, amparado en un dispositivo jurídico-legal y un aparato institucional específico (Ley 70 para las comunidades negras, Ley 60 para los indígenas, leyes fundamentales de la propiedad privada para los agroempresarios). La fragmentación territorial, étnica y política tiene entonces sustento legal, cuando los habitantes de los distintos tipos de territorios no se acogen a las mismas legislaciones.

De hecho, los conflictos entre organizaciones étnico-territoriales negras y grupos indígenas - sean familias o resguardos enteros - se multiplican a medida que se confirman las titulaciones de territorios colectivos (sobre todo en Chocó). En Nariño los conflictos oponen principalmente los consejos comunitarios a empre- 
sarios agroindustriales palmicultores. Estos últimos se apoyan en las políticas nacionales de desarrollo de la agricultura comercial para afianzar su presencia iniciada en los años 1950 y proseguir una expansión espectacular en los últimos meses, en especial en la región del Mira. Compitiendo por espacio con proyectos de territorios colectivos, promueven entre los pequeños agricultores negros un proyecto de desarrollo agrícola en asociación con ellos, prometiéndoles crédito, asesoría técnica y garantía de compra del producto. Les ofrecen además ciertas facilidades para titulaciones individuales de sus parcelas, con lo que se enfrentan brutalmente a los Consejos Comunitarios que gestionan la titulación colectiva sobre las mismas tierras. En efecto, en la lógica agroindustrial, la consolidación de los derechos de propiedad es condición necesaria para suscitar mayor circulación de bienes, productos y trabajadores, e integrar a los pobladores negros en su sistema de producción. Ambos "proyectos", el empresarial y el étnico-territorial, se enfrentan en condiciones de enorme desigualdad de recursos económicos y políticos. El primero goza de capital propio y apoyo nacional indefectible, mientras el segundo difícilmente logra reunir esfuerzos y voluntades para construir un proyecto alternativo.

Hace unos meses (en Agier, Barbary, Hoffmann, Quintín, Ramírez y Urrea, "Espacios regionales, movilidad y urbanización, dinámicas culturales e identidades en las poblaciones afrocolombianas del Pacifico sur y Cali. Una perspectiva integrada”. Informe final para COLCIENCIAS, del Proyecto CIDSE-IRD a COLCIENCIAS, 2000), podíamos presentar así las tendencias opuestas de un dispositivo socio-espacial muy original, y discutir sobre sus posibles desarrollos. En aquel momento nos preguntábamos: ¿cuánto tiempo puede durar esta situación "esquizofrénica", donde cohabitan en un mismo espacio actores anclados en lógicas de poder y de expansión territorial, bien armados aunque sea con armas de distintos tipos (económica, política, militar)? Todo parece indicar que ya tenemos respuesta, y que la historia regional se fue por el camino del enfrentamiento y la violencia, como veremos a continuación.

\section{Conclusión: el devenir ya es pasado. Una región hacia la anomia}

En los últimos meses la situación se ha vuelto preocupante. Los cultivos de coca se extienden en los campos. El control de las 
tierras bajas productoras de coca por un lado, y la constitución de un corredor entre la zona de despeje de las FARC y el Oceano Pacífico por otro, ${ }^{14}$ llevan las guerrillas a acentuar su presión sobre el pacífico. Al mismo tiempo, las fuerzas paramilitares, presentes desde hace algunos años en la zona de Tumaco, ${ }^{15}$ buscan oponerse a estas tentativas y amenazan a todos los "activistas" de la sociedad civil, incluyendo en estos a los militantes étnicos, sus asesores de ONG o de la Iglesia Católica, los sindicalistas, etc. El ejército abandonó en los años recientes sus bases de Caunapí y de Candelilla de la Mar -esta última pronto recuperada por paramilitarespero refuerza su presencia en la ciudad de Tumaco con la creación reciente de una unidad naval que tendría a su cargo el control de la zona de frontera internacional. ${ }^{16}$ Finalmente, denuncias reiteradas conciernen a los grandes agentes económicos que, sintiéndose amenazados por la situación de crisis, pagan actores armados por su protección a la vez que aprovechan la situación para ampliar sus capitales. En particular, la palmicultura busca expandirse, como lo acabamos de ver, compitiendo por el espacio con los futuros territorios colectivos de los Consejos Comunitarios negros.

Asumo el riesgo de alimentar el "pensamiento apocalíptico", pero quiero precisar que esta interpretación reposa en hechos comprobados. Asesinatos selectivos, desplazamientos colectivos, amenazas a líderes que buscan refugio en las capitales y hasta masacres son denunciados por ONGs serias (Amnesty Internacional) como por la Iglesia: en Llorente-Tumaco en febrero 2001, en el Alto Naya en abril del mismo año (acciones "compartidas" entre fuerzas guerrilleras y paramilitares), en Imbili-Mira también en 2001... El 19 de septiembre 2001 fue asesinada Yolanda Cerón, que era pilar del trabajo de la Pastoral con las comunidades negras en Nariño.

La región parece seguir un proceso de "aborto regional", de dislocación social, política y territorial. Las personas y grupos involucrados en los movimientos sociales no pueden competir con los recursos que se ofrecen por parte de los agentes legales (los palmicultores) o ilegales (la coca o los paramilitares). En situaciones económicas de extrema precariedad, las poblaciones tanto rurales como urbanas pueden vislumbrar estas alternativas como una solución a corto plazo a sus dificultades del momento, y se alejan de cualquier movilización que les exija tiempo y recursos, sin ofrecer garantía de éxito. Por su parte, las dinámicas políticas "tradicionales" (político-electorales esencialmente) parecen volver a sus cauces antiguos marcados por el clientelismo. Después de un "inter- 
medio" cívico en el que se eligió un alcalde nativo y cercano al sector popular de Tumaco (Newton Valencia, 1997-2000), el debate político local se reduce de nuevo a un enfrentamiento entre las tres facciones del liberalismo que se comparten el poder local desde hace décadas (cf. Hoffmann, 1999a).

El manejo complejo del espacio por parte de los distintos actores locales y regionales nos lleva a plantear la categoría de "capital espacial", siguiendo a Levy (1994): un capital multivalor (polyvalent), que como cualquier capital es "canjeable", es decir susceptible de generar intereses "realizables" bajo otras modalidades, políticas y económicas principalmente, pero también en capital social o capital cultural (cf. Levy, 1994). En el contexto nacional colombiano esta categoría analítica es de evidente pertinencia para entender las actuaciones de los grupos guerrilleros y paramilitares en el marco de las negociaciones de paz; el control territorial es decisivo para adquirir poder de negociación, la zona de despeje se volvió uno de los capitales más estratégico de los que disponen las FARC en la actualidad.

En el Pacífico se vuelve asimismo una noción que ayuda a entender los procesos contradictorios que se tejen alrededor de las reivindicaciones étnicas. Los territorios colectivos representan a menudo, para las poblaciones rurales negras que ya lograron la titulación, su único capital reconocido por las agencias gubernamentales. Se volvieron así un recurso para acceder al mundo de las instituciones, pero en el mismo momento son también un escenario de competencia con los vecinos. El "espacio étnico" es ahora codiciado y peleado en cuanto tal, mientras el mismo espacio geográfico se ha vuelto objeto de inversiones financieras cuantiosas por parte de actores foráneos a la región. El control y la apropiación del espacio es objeto de negociación y competición, arreglos, y acciones llevadas por actores que disponen de medios disproporcionados entre sí y tienen objetivos variados (movimientos sociales, pero también acciones individuales, sociedad civil, partidos, etc).

Los procesos de transformación socio-espacial que hemos descrito, y los esquemas que presentamos para cada configuración, demuestran una vez más que el espacio geográfico no determina nunca, de por sí, dinámicas sociales o políticas particulares, pero que éstas tampoco se pueden librar de la dimensión espacial. Los ejemplos citados mostraron como un territorio marginado y aislado se vuelve estratégico en el marco del conflicto armado, cuando otra microregión decae por culpa de una iniciativa individual que le quitó todos sus recursos (el canal Naranjo). Algunas políticas 
conciernen tierras y espacios concretos (los ríos) mientras otras se fundan en criterios étnicos, pero todas tienen consecuencias sobre la organización regional. La morfología del espacio regional cambia según las funciones que asumen sus distintas partes para los distintos actores, en un contexto histórico dado.

Las dinámicas socio-espaciales se asocian a cambios de otro orden, sea económico, cultural o político. En estas interacciones el análisis evidenció procesos de retroalimentación entre los niveles del centro y de las periferias, de lo local y de lo global. Las transformaciones político-étnicas, por ejemplo, suponen procesos creativos por parte de los actores individuales y colectivos que intervienen en ellas, como pueden ser procesos de invención/recuperación de la tradición para algunos, o de elaboración de nuevos esquemas de participación ciudadana para otros. En ambos casos exige de los actores, campesinos de base o dirigentes de organización étnico-territorial, una cierta capacidad para jugar con los distintos niveles y registros de legitimación.

Por otra parte, los actores intervienen con capitales sociales, políticos, económicos y culturales variados y sumamente desiguales. La negociación entre los actores locales, entre ellos y el Estado o los actores regionales, es en sí una innovación que requiere de un aprendizaje, a veces brusco e incluso violento. En este proceso de aprendizaje aparece una nueva categoría "sociopolítica": la de los mediadores ("brokers" en ingles o "courtiers" en francés), compuesta por asesores, dirigentes, militantes de ong's o expertos locales. Son personas capaces de manejar lenguajes distintos y de elaborar "traducciones" entre dos mundos (por ejemplo el campesino y el administrativo, o el empresarial y el político), y sobre todo son gente que "saben" de los dos mundos, porque, de alguna manera, pertenecen a ambos. En momentos de fuerte recomposición como es el caso en Colombia, se vuelven rápidamente actores políticos que aspiran a recomponer los escenarios políticos y las maneras de intervenir en ellos. En el Pacífico, son ellos los que difunden los discursos "universales" (etnicidad, derechos humanos, medioambiente, biodiversidad) hacia el campo, a la vez que controlan los recursos monetarios que están asociados a través de la elaboración de múltiples "proyectos" que hoy estructuran la vida asociativa en el Pacífico como en otras regiones del país y del planeta.

La "modernización" (escolarización, comunicación, entrada de capital) y la "modernidad" (etnicización, ecologización de los discursos) implican nuevos modelos de sociabilidad en los que "la Ciudad” juega un papel preponderante. La urbanización de las po- 
blaciones del Pacífico es un hecho que ya no se puede menospreciar, tanto en las regiones (Buenaventura, Quibdó, Guapi, Tumaco) como en las principales ciudades del país, por efecto de las migraciones. Cali, destino principal de los migrantes del Pacífico sur, adquiere una posición central en el dispositivo socio-migratorio de nivel macroregional y aun nacional (cf. artículo de FU-OB). Estos cambios vuelven más complejas las construcciones identitarias que se han elaborado principalmente, hasta hoy y para las comunidades negras, desde lo rural y lo territorial (cf. artículo de Agier y Quintín en este mismo número), pero que atañen a toda la población afrocolombiana.

\section{Notas}

1. Este análisis da cuenta de los resultados del proyecto de investigación llevado a cabo entre 1996 y 2000, por el CIDSE-Universidad del Valle (Colombia) y el IRD (Francia): "Organización social, dinámicas culturales e identidades de las poblaciones afrocolombianas del pacífico y suroccidente en un contexto de movilidad y urbanización”, coordinado por F.Urrea y M.Agier, en el cual participaron media docena de investigadores. En este artículo me refiero básicamente a resultados obtenidos por N. Rivas, socióloga, C. Agudelo, también sociólogo, y yo, geógrafa. Otros investigadores aportaron elementos, los menciono en el texto.

2. Cf. el modelo aldeano parental de Gilma Mosquera y Jacques Aprile (1999).

3. Estas características también se habían recalcado, desde otro punto de vista, en el trabajo de Restrepo en la costa norte de Nariño (Restrepo y del Valle,1996).

4. Al contrario de lo que encontró Nancy Motta por ejemplo, en el Salahonda de los años 1970, lo que la llevó a interpretar las dinámicas familiares en términos de matrifocalidad y alta movilidad matrimonial. Cf. Motta (1975).

5. Coincidiendo con lo encontrado por Mosquera y Aprile (1999).

6. Este cuestionamiento también se dio, en el proyecto, desde otro enfoque, con las miradas antropológicas de Pedro Quintín (1999) y las de Alfredo Vanín (1999) sobre migración.

7. Es por esta razón que no usamos el término "territorio" en esta configuración socio-espacial; en cambio, será fundamental en el tercer modelo analizado, el de la movilización política, que se construyó en gran parte sobre esta noción.

8. A tal punto que hoy los municipios del norte reclaman su secesión de Nariño para acogerse al Departamento del Valle (El País, 2 de julio de 1999).

9. En la ensenada de Tumaco, cf. Arocha (1999).

10. Entre las medidas importantes asociadas a la ley de descentralización está la elección de alcaldes populares, en lugar del nombramiento de los alcaldes por el gobernador del Departamento, como era antes.

11. Corporación para el Valle del Cauca. Institución encargada de los proyectos de desarrollo en la parte sur del Pacífico colombiano hasta fines de los 1990 en que se constituyen corporaciones en cada departamento. En Nariño, la CVC fue particularmen- 
te activa en la década de los noventa, por sus programas de desarrollo rural en cooperación con Holanda.

12. En 1988 unas manifestaciones en contra del deterioro del servicio público en Tumaco terminan por una confrontación violenta en el centro de la ciudad, la destrucción de edificios públicos, varios incendios y hasta una persona muerta. Este episodio es conocido como "el Tumacazo" en referencia al Bogotazo, de 1948, que marcó el inicio de la violencia en Colombia.

13. La concepción de "comunidad" cerrada y autónoma, y su evolución hacia la integración a la "sociedad", fue desarrollada, entre otros, por Redfield, Robert (1944).

14. En una entrevista con un periodista en mayo 1999, Marulanda expresaba claramente las aspiraciones de las FARC a controlar una vía al mar en la zona sur del país.

15. Los paramilitares anunciaron su llegada a Tumaco "para el 10 de enero de 1999" (vox populi) y empezaron acciones de "limpieza social" contra delincuentes el año siguiente.

16. Muchos son los que denuncian incursiones del ejército en el tráfico de coca en la zona, y sus lazos con los paramilitares.

\section{Bibliografía}

AGIER, Michel (1999a). "Pérdida de lugar, despojo y urbanización. Un estudio sobre los desplazados en Colombia”. In F. Cubides y C. Domínguez (eds.) Desplazados, migraciones internas y reestructuraciones territoriales. Bogotá, CES/Universidad Nacional, pp.104-126.

AGIER, Michel (1999b). ¿Cómo hacer ciudad en el nuevo siglo?. In M. Agier, M. Alvarez, O. Hoffmann y E. Restrepo, Tumaco: haciendo ciudad. Historia, cultura e identidad. Bogotá, Ican/Ird/Universidad del Valle/Colciencias, pp. 279-286.

AGIER, Michel y HOFFMANN, Odile (1999). "Les terres des communautés noires dans le pacifique colombien. Interprétations de la loi et stratégies d'acteurs". Problèmes d'Amérique Latine, $\mathrm{n}^{\circ}$ 32, janvier-mars, La Documentation Française, Paris, pp.17-42.

AGIER, M.; BARBARY, O.; HOFFMANN, O.; QUINTÍN, P.; RAMÍREZ, H. F., y URREA, F. (2000). "Espacios regionales, movilidad y urbanización, dinámicas culturales e identidades en las poblaciones afrocolombianas del Pacifico sur y Cali. Una perspectiva integrada. Informe final para COLCIENCIAS”. Cali, Cidse/IRD, 88p.

AGUDELO, Carlos (1999). "Colombie: changement constitutionnel et organisation des mouvements noirs". Problèmes d’Amérique Latine, nº 32, jan.-mar., La Documentation Française, pp.43-52.

ALVAREZ, Manuela (1998). "Prácticas espaciales y regímenes de construcción de la ciudad de Tumaco". In Juana Camacho y Eduardo Restrepo (eds), De montes, rios y ciudades. Territorios e identidades de la gente negra en Colombia. Bogotá, Fundación Natura-ECOFONDO-ICAN, pp. 193-220.

APRILE, Jacques (1992a). La ciudad Colombiana: siglo XIX y siglo XX. Biblioteca Banco Popular, Bogotá.

APRILE, Jacques (1992b). "La colonización del Chocó". Colonización del bosque húmedo tropical. Corporación de Aracuara. Bogotá. 
ARBOLEDA, Santiago (2001). "Paisanajes, colonias y movilización social afrocolombiana en el suroccidente". Simposio internacional "Pasado, presente y futuro de los afrodescendientes". U. Nacional-IRD-ICANH, Cartagena de Indias, 18-19-20 de octubre.

AROCHA Jaime (1999). Ombligados de Ananse. Hilos ancestrales y modernos en el Pacífico colombiano, U. Nacional-CES, Bogotá, 204p.

CEGA (Centro de Estudios Ganaderos) (1999). Análisis de factibilidad y diseño institucional para el desarrollo de cinco núcleos de cultivo de palma de aceite en Tumaco, Nariño. Informe de la consultoría, Bogotá, septiembre.

ESCOBAR, Arturo (1996). "Viejas y nuevas formas de capital y los dilemas de la biodiversidad”. In A. Escobar y A. Pedroza (invest.), Pacífico ¿Desarrollo o diversidad? Estado, capital y movimientos en el Pacífico colombiano, ECOFONDO-CEREC, Bogotá, pp. 109-131.

GRUZINSKI, Serge (1999). La pensée métisse. Fayard, Paris.

HELFRICH, Linda (1998). Elecciones: entre gamonalismo y civismo. El caso de Tumaco en la costa pacífica. Documento IEPRI, multigr.

HOFFMANN, Odile (1998). "Políticas agrarias, reformas del Estado y adscripciones identitarias: Colombia y México”. Análisis Político, nº 34, IEPRI, Bogotá, pp. 2-24.

HOFFMANN, Odile (1999a). "Identidades locales, identidades negra: la conformación del campo político en Tumaco (1950-1998)”. In M. Agier, M. Alvarez, O. Hoffmann y E. Restrepo, Tumaco: haciendo ciudad. Historia, cultura e identidad. Ican/Ird/Universidad del Valle/Colciencias, Bogotá, pp. 245-276. .

HOFFMANN, Odile (1999b). "Territorialidades y alianzas: construcción y activación de espacios locales en el Pacífico". In J. Camacho y E. Restrepo (eds), De montes, ríos $y$ ciudades. Territorios e identidades de la gente negra en Colombia. Natura/Ecofondo/Ican, Bogotá, pp.75-94.

HOFFMANN, Odile (2001). "Del territorio étnico a la ciudad: las expresiones de identidad negra en Colombia a principios del siglo XXI”. II Seminario Internacional sobre Territorio y Cultura, Manizales, U. de Caldas, Colombia, 23 y 24 de octubre.

INCORA (2001). Informe a Durban, Conferencia contra el racismo, la xenofobia....

LEVY, Jacques (1994). L'espace légitime. Presses de la Fondation de Sciences Politiques, Paris, 442p.

LOSONZCY, Anne-Marie (1997). Les saints et la forêt. Rituel, société et figures de l'échange avec les indiens emberá chez les Négro-Colombiens du Chocó. L'Harmattan, Paris, 419p.

MOSQUERA, Gilma (2000). "Sobre el sistema urbano-aldeano del pacífico”. Cuadernos del CITCE, Serie Investigaciones $n^{\circ}$ 4, UniValle, Cali, 92p.

MOSQUERA, Gilma y APRILE, Jacques (1999). "Hábitats y habitantes del Pacífico, Síntesis y reflexiones finales”. Cuadernos CITCE, Serie Investigaciones n², Cali, UniValle, $87 \mathrm{p}$.

MOTTA, Nancy (1975). Estratificación social en Salahonda. Tesis, Universidad del Cauca, Popayán.

OSLENDER, Ulrich (1998). "Espacio e identidad en el Pacífico colombiano". In Juana Camacho y Eduardo Restrepo (eds), De montes, ríos y ciudades. Territorios e identida- 
des de la gente negra en Colombia. Fundación Natura-ECOFONDO-ICAN, Bogotá, pp. 25-48.

PARDO, Mauricio (1997). "Movimientos sociales y actores no-gubernamentales". In M. Uribe y E.Restrepo (eds), Antropología en la modernidad. ICAN-Colcultura, Bogotá, pp. 207-252.

QUINTÍN, Pedro (1999). “Memorias y relatos de lugares: a propósito de una migrante de la costa pacífica en Cali”. In J. Camacho y E. Restrepo (eds), De montes, ríos y ciudades. Territorios e identidades de la gente negra en Colombia. Natura/Ecofondo/Ican, Bogotá, pp.245-262.

REDFIELD, Robert (1944). Yucatán, una cultura de transición. México, Fondo de Cultura Económica.

RESTREPO, Eduardo (1997). "Unos bosques sembrados de aserríos, la industria maderera en el Pacífico colombiano”. Informe al Proyecto Biopacífico, Bogotá, 257p

RESTREPO, Eduardo (1999). "Hacia la periodización de la historia de Tumaco". In M. Agier, M. Alvarez, O. Hoffmann y E. Restrepo, Tumaco: haciendo ciudad. Historia, cultura e identidad. Ican/Ird/Universidad del Valle/Colciencias, Bogotá, pp. 54-86.

RESTREPO, Eduardo y DEL VALLE, Jorge I. (eds) (1996). Renacientes del guandal: "grupos negros" de los ríos Satinga y Sanquianga. Proyecto Biopacífico-U.Nacional, Bogotá, 473p.

RIVAS, Nelly (1999). "Modalidades de acceso a la tierra en el Pacífico nariñense: río Mejicano-Tumaco”. In J. Camacho y E. Restrepo (eds), De montes, ríos y ciudades. Territorios e identidades de la gente negra en Colombia. Natura/Ecofondo/Ican, Bogotá, pp.95-106.

RIVAS, Nelly (2000). "Ley 70, medio ambiente y relaciones intra-municipales: El consejo comunitario ACAPA, pacífico nariñense”. In VV.AA., Impactos de la ley 70 y dinámicas políticas locales de las poblaciones afrocolombianas: Estudios de caso. Documento de Trabajo ${ }^{\circ}$ 50, CIDSE-IRD, UniValle, Cali, pp.1-28.

SÁNCHEZ, John Antón (2001). "La estrategia étnica afrocolombiana en el Pacífico: conflicto, territorio y región". II Seminario Internacional sobre Territorio y Cultura, Manizales, U. de Caldas, Colombia, 23 y 24 de octubre.

TÖNNIES, Ferdinand (1977 [1922]). Communauté et société. Catégories fondamentales de la sociologie pure. Paris, Les Presses universitaires de France, 286 p.

URREA, Fernando (1999). "Algunas características sociodemográficas de los individuos y hogares Afrocolombianos en Cali". InVV.AA., Afrocolombianos en el área metropolitana de Cali. Estudios sociodemográficos. Documento de Trabajo nº 38, CIDSE-IRD, UniValle, Cali, pp.63-98.

URREA, Fernando y MURILLO, Fernando (1999). "Dinámica del poblamiento y algunas características de los asentamientos populares con población afrocolombiana en el oriente de Cali”. In F. Cubides y C. Domínguez (eds.) Desplazados, migraciones internas y reestructuraciones territoriales. CES-Universidad Nacional, Bogotá, pp. 337-405.

URREA, Fernando; RAMÍREZ, H. F., y VIÁFARA, C. A. (2001). "Perfiles sociodemográficos de la población afrocolombiana en contextos urbano-regionales del país a comienzos del siglo XXI". Ponencia presentada en el simposio "Estado del arte de los 


\section{Odile Hoffmann}

estudios afrocolombianos", organizado por la especialización de "Estudios Afrocolombianos”, de la Universidad del Cauca, Popayán, noviembre, 65 p.

VANIN, Alfredo (1999). "Alianzas y simbolismos en las rutas de los ausentes". In VV. AA. Imágenes de las "culturas negras" en el Pacífico colombiano. Documento de Trabajo no 40, CIDSE-IRD, UniValle, Cali, pp. 3-14.

VILLA, William (1998). "Movimiento social de comunidades negras en el Pacífico colombiano. La construcción de una noción de territorio y región”. In Geografía humana de Colombia. Tomo VI: "Los Afrocolombianos". Inst. Colombiano de Cultura Hispánica, Bogotá, pp. 431-449.

WADE, Peter (1994). "Identités noires, identités indiennes en Colombie". Cahiers des Amériques Latines, $\mathrm{n}^{\circ}$ 17, Paris, IHEAL, pp. 125-140.

WEST, Robert (1957). The lowlands of Colombia. Louisiana State University Studies, Baton Rouge. 